\title{
Corrupción en las instituciones. Un llamado urgente de renovación y transparencia
}

\author{
SONIA BRITO RODRÍGUEZ* \\ Universidad Católica Silva Henríquez (Chile) \\ sbritor@ucsh.cl \\ ÁlVARO RAMIS OLIVOS** \\ Universidad Academia de Humanismo Cristiano (Chile) \\ aramiso@docentes.academia.cl
}

\begin{abstract}
Resumen
El presente artículo busca problematizar la corrupción institucional desde una perspectiva sistémica. Examina su alcance y sus implicaciones ético-sociales para proporcionar una interpretación clave, que analice la crisis de la Iglesia católica chilena. Para este propósito se utiliza una metodología bibliográfica que revisa a autores contemporáneos que trabajan en la ética de las instituciones, identificando elementos fundamentales para entender la corrupción institucional. También repasa el magisterio del Papa Francisco, quien da pistas para enfrentarla. Se propone, junto con una necesaria renovación eclesiológica, nuevas perspectivas éticas de organización institucional, basadas en el buen gobierno y la transparencia.
\end{abstract}

Palabras clave: Corrupción, institución eclesial, encubrimiento, gobernanza y transparencia.

\section{Corruption in the ecclesial institution. An urgent call for renewal and transparency}

\begin{abstract}
The paper seeks to problematize institutional corruption from a systemic perspective. It examines its scope and ethical-social implications, to provide a key interpretation that analyzes the crisis of the Chilean Catholic Church. For this purpose a bibliographic methodology is used, reviewing contemporary authors who work on the ethics of institutions, identifying fundamental elements to understand institutional corruption. He also reviews the teaching of Pope Francis, who gives clues to face it. It is proposed along with a necessary ecclesiological renewal, new ethical perspectives of institutional organization, based on good governance and transparency.
\end{abstract}

Key words: Corruption, ecclesiastical institution, concealment, governance and transparency.

\footnotetext{
* Doctora en Ciencias de la Educación, mención Educación intercultural, Universidad de Santiago de Chile. Académica-investigadora, Encargada de Formación Identitaria Personal de Gestión, Universidad Católica Silva Henríquez (UCSH).

** Doctor en Ética y Democracia, Universidad de Valencia (España); Máster en cuestiones contemporáneas de DDHH, U. Pablo de Olavide -Sevilla. Académico Escuela de Ciencia Política Universidad Academia de Humanismo Cristiano. Autor del libro Bienes comunes y democracia. Crítica del individualismo posesivo (2017).
} 
INTRODUCCIÓN

La compleja situación eclesial que enfrenta la Iglesia chilena, se ha presentado generalmente con el adjetivo crisis, sin embargo, muchas veces no se ha precisado el alcance de ésta, o bien, se les ha reducido a los abusos sexuales cometidos por algunos integrantes de la jerarquía. En este sentido, el artículo parte de la base que la denominada crisis eclesial posee diversas aristas, una de ellas es el escándalo de los abusos sexuales, sin embargo, la crisis es sistémica, pues el mismo Papa Francisco (2018a), luego de conocer los antecedentes del Informe Scicluna, ha afirmado que los abusos sexuales fueron posibles porque en la iglesia chilena ha existido abuso de poder y de conciencia.

Esta situación ha llevado a una crisis interna, más allá de las elucubraciones teóricas de renovación eclesial que diversas líneas teológicas plantearon después del Concilio Vaticano II que en palabras de Scannone (2016: 181) formaría parte de "la agenda inacabada del Concilio", ahora se trata de una realidad de corrupción, reconocida por el mismo Papa Francisco cuando invita al Pueblo de Dios que peregrina en Chile a nacer de nuevo, evocando el texto de Jn 3,8, en su diálogo con Nicodemo y señalando que el Espíritu Santo: “está continuamente en movimiento para ensanchar las miradas estrechas, hacer soñar al que perdió la esperanza, hacer justicia en la verdad y en la caridad, purificar del pecado y la corrupción e invitar siempre a la necesaria conversión" (Francisco, 2018a: n.2). Por tanto, se trata de un modo de hacer iglesia que no es posible seguir sosteniendo y que se hace trizas por la fuerza de los acontecimientos que no son sólo pecados que lesionan el amor evangélico y retrasan la construcción del Reino, sino que se trata de delitos personales y corrupciones estructurales.

Esta crisis interna de la Iglesia a nivel universal ha sido denunciada, entre otros, por autores como Küng (2013: 17) cuando plantea derechamente que "así no se puede seguir" o en un plano más local cuando Costadoat (2014: 74) propone una iglesia "2.0". Ambos autores sitúan la crisis en la jerarquía de la iglesia y sobre todo de aquellos grupos integristas que, amparados en su envestidura, han dañado la imagen de credibilidad en la institución y han dejado una profunda desazón en el pueblo de Dios. Por tanto, el fenómeno de la crisis alcanza los ribetes de corrupción en la institución eclesial, donde se hace necesario distinguirla de la iglesia que es propiamente el pueblo de Dios, constituida por todos los bautizados. Por este motivo, es que en el artículo se utilizará el concepto de institución eclesial para referirse a la dimensión jerárquica de la iglesia que han tenido por siglos la labor de gobernar, gestionar y administrar, diferenciándola de la iglesia como comunidad de los bautizados. 
Junto a esta crisis interna, se desarrolla al mismo tiempo una crisis externa, que surge desde el momento en que tanto la sociedad civil, como los medios de comunicación empatizaron con quienes se constituyeron en punta de lanza en la denuncia de los abusos sexuales, lo que fue generando efectos multiplicadores y de denuncia social. Es así que el país experimenta una inquietante e incesante búsqueda de la verdad que se devela a ojos abiertos, como un gran escándalo social a través de la denuncia de las víctimas y recogiendo los testimonios espeluznantes de los sobrevivientes de los abusos. Así, los medios de comunicación han sido la plataforma para develar esta red, a través de investigaciones serias y profundas para seguir recabando informaciones no sólo de abusos sexuales, sino también de corrupción y encubrimiento.

En el marco de este contexto social y épocal, la ciudadanía entiende esta crisis como corrupción institucional, porque se va descubriendo una red de protección y encubrimiento al delito, donde la institución, en sí misma, no demuestra tener la capacidad de transparencia, ni de autoevaluarse ni de autosanarse. Es más, es la sociedad civil a través del poder judicial y los medios de comunicación, los que presionan a la institución eclesial a tomar una postura y a tomar las decisiones pertinentes ante la gravedad del delito.

La crisis con rostro de corrupción es un problema a nivel país, pues, independiente de si los ciudadanos se declaran creyentes o no, la institución eclesiástica es un sujeto social que actualmente es responsable de diversas organizaciones tales como fundaciones, jardines infantiles, colegios, universidades, hogares de niños y ancianos, parroquias, entre otras. Por tanto, el debate, requiere un análisis profundo, considerando diversos aspectos tales como la corrupción, el encubrimiento, el delito, el autoritarismo, el elitismo y el abuso de poder, de conciencia y sexual. De tal forma que, como invita el Papa Francisco, es necesario discernir:

para llegar a las raíces que permitieron que tales atrocidades se produjeran y perpetuasen, y así encontrar soluciones al escándalo de los abusos no con estrategias meramente de contención -imprescindibles pero insuficientessino con todas las medidas necesarias para poder asumir el problema en su complejidad (2018b: n. 3).

Desde esta invitación del Papa, es que el artículo busca aportar desde la ética de las instituciones a la problemática de la corrupción y de esa forma entregar algunas claves de lectura para comprender la situación de la institución eclesial y esbozar algunos caminos de solución. Para alcanzar este objetivo, parece oportuno trabajar con algunos autores que desde la ética aplicada de las instituciones contribuyen en la aclaración del concepto 
de corrupción y su alcance ético, sugiriendo como solución recurrir al recurso moral y al bien interno. Por su parte, la eclesiología del Papa Francisco que ha impulsado desde la carta programática de Evangelii Gaudium rescata lo propio de la Iglesia como comunidad de los creyentes en Cristo, la conversión permanente y la misión al servicio de la humanidad. Ambos elementos, permiten entregar una propuesta a partir de los pilares de la gobernanza y la transparencia.

Las fuentes documentales se ordenarán a partir del desarrollo del artículo en tres apartados, a saber, ética y corrupción institucional, corrupción en la institución eclesial y propuesta de renovación a partir de la gobernanza y la transparencia.

\section{1. ÉTICA Y CORRUPCIÓN INSTITUCIONAL}

En el siguiente apartado la temática de la corrupción en las instituciones se abordará desde tres dimensiones: definiciones y perspectivas; corrupción y ética institucional; bienes internos y bienes externos en las instituciones.

\subsection{Definiciones y perspectivas}

Las definiciones tradicionales de corrupción no siempre apuntan al carácter sistémico del problema. Por ejemplo, el Banco Mundial ha definido "corrupción" en algunos de sus documentos como el "abuso del cargo público para el beneficio privado" (World Bank, 2014: xi). Esta conceptualización radica la responsabilidad exclusivamente en individuos, preferentemente políticos y funcionarios del Estado. Queda oculto que cualquier proceso corruptor exige la participación de más de una persona, incluyendo una parte corruptora. Otra definición que puede aparecer más completa sería abuso del poder en beneficio propio (García Marzá, 2017). Esta mirada describe de una manera más integral el fenómeno, ya que abarca a cualquier individuo que abuse de una posición para su propio interés. El problema es que la noción de "abuso" posee una connotación episódica. Dentro de una serie de prácticas adecuadas el abuso sería el tipo de práctica excesiva que se podría interpretar como aislada y poco frecuente. Pero, si lo que se observa y analiza son prácticas persistentes y generalizadas no cabe hablar de abusos, sino de malos usos, normalizados por su carácter sistémico e institucionalizado.

Es evidente que en nuestra sociedad cunden fuertes críticas en contra de la baja moralidad de muchas instituciones, según documentó el Consejo 
Asesor Presidencial Contra los Conflictos de Interés, el Tráfico de Influencias y la Corrupción, que emitió su informe en abril de 2015. Se trata de observaciones fundadas, que apuntan en contra de conductas que operan en la política, la economía y en las instituciones sociales, culturales y religiosas, incluyendo a la Iglesia Católica. Se advierte en ellas de la corrupción, el tráfico de influencias, la falta de responsabilidad y criterio, la falta de transparencia, abusos y malos manejos, ausencia de compasión por quienes son más débiles y no tienen recursos, ni poder. Sin embargo, estas críticas requieren de ciertas definiciones compartidas para adquirir fuerza transformadora, ya que, en una sociedad plural no se dispone a priori de convicciones morales comunes. ¿Cómo puede responder aquella institución a la que se critica si se parte de una convicción moral particular, igualmente respetable que otra, pero diametralmente distinta de las convicciones de quien realiza esa crítica? Es posible que tras el tupido enjambre de recriminaciones morales de la actualidad se instale un diálogo sordo, que impida regenerar las instituciones y prácticas cuestionadas.

En contra de los subjetivismos absolutos, no parece razonable argumentar que todo sea opinable y sujeto al perspectivismo contextual, como se podría suponer en esta materia. Es posible arribar a un marco mínimo de exigencias éticas y valores comunes, sobre la base de los cuales sea posible argumentar y llegar a acuerdos intersubjetivos vinculantes. Un piso evidente es el respeto a los deberes legales: se trata de asumir que a pesar de su irreductible imperfección el Estado de Derecho permite delimitar unos márgenes de facticidad jurídica tanto en lo que respecta a lo que está prohibido como también a lo que ese mismo marco de leyes permite. Aunque no se comparta ninguna convicción moral, al menos la ciudadanía y las instituciones no tienen más remedio que atenerse a las leyes convenidas, porque en caso contrario, existirá una sanción por parte de la autoridad competente.

Por otra parte, es evidente que el imperativo legal es insuficiente para definir la corrupción institucional. Los referentes legales y normativos no bastan para poner límite a conductas deshonestas. El derecho, la legalidad vigente válida para todos, es una exigencia mínima, pero que no agota los dilemas a los que debe dar cuenta la actualidad. Tampoco basta con apelar al valor normativo de la religión, ya que sólo cabe señalar su imperio para los creyentes, y aún dentro de ellos, su pretensión de validez moral se debe interpretar dentro de una hermenéutica determinada de la doctrina. Si ley y religión fueran suficientes a la hora de tomar decisiones institucionales, líderes eclesiales, políticos, empresarios, médicos, docentes y los restantes actores sociales, tendrían suficiente con respetar la legalidad o, en el caso de los creyentes, aplicar la doctrina de su Iglesia. Pero la realidad muestra que no todos los casos de corrupción o deshonestidad son delito jurídico 
o pecado religioso. Hay, pues, un lugar específico para la ética de las instituciones (García Marzá, 2004: 34).

\subsection{Corrupción y ética institucional}

¿Cuáles pueden ser los marcos comunes que permiten delimitar una ética de estas características? En primer lugar, se deben identificar las exigencias de las "éticas universalistas" (Ramis, 2017: 253) que permiten establecer una deontología racional, formal, postmetafísica, propicia para sociedades plurales. Una de estas propuestas es la articulación procedimental de la ética discursiva, que propone una racionalidad que busca llegar a consensos a través de una argumentación sin coacción, tal como se desprende de la ética del discurso planteada por Habermas: "en los contextos de acción comunicativa solo puede ser considerado capaz de responder de sus actos aquel que sea capaz, como miembro de una comunidad de comunicación, de orientar su acción por pretensiones de validez intersubjetivamente reconocidas" (Habermas, 1999: 33).

Desde esta perspectiva es posible deliberar "dentro de cada una de las éticas aplicadas" (Martínez Navarro, 2000: 39) distinguiendo tres esferas simultáneas, interrelacionadas, pero a la vez diferenciadas:

- Un nivel macro, que aborde cuestiones comunes respondiendo a valores, derechos, o actitudes universalizables.

- En segundo lugar, a un nivel meso, en el cual las instituciones y organizaciones adquieren forma concreta a partir del entramado normativo, jurídico y cultural que le es propio.

- Y a un nivel micro, en el cual opera el individuo concreto, en interacción y socialización permanente.

Esta fundamentación, presupone la existencia de una sociedad secular, con una esfera pública, un conjunto de espacios comunicativos - separados nítidamente del Estado y del mercado- alrededor de los cuales los ciudadanos forman, a través del diálogo y del ejercicio racional de la crítica, una opinión común sobre temas de interés colectivo (Habermas, 1985). Los afectados por decisiones de instituciones privadas, pero que, como las Iglesias poseen responsabilidades públicas, aspiran a ser considerados interlocutores válidos e incorporados en el proceso decisional que les atañe. Las condiciones para esta incorporación se deben regir de acuerdo a las pretensiones de validez que Habermas (1999) establece de acuerdo a la pragmática universal del habla, a saber: inteligibilidad, verdad, veracidad y rectitud normativa. Condiciones que incorpora en el horizonte 
de la llamada "situación ideal de habla", entendida como presupuesto regulativo contrafáctico, capaz de satisfacer intereses universalizables. Este requerimiento explica el llamado "giro aplicado" (Cortina, 1985) de la ética, que ha permitido que la deliberación interdisciplinar intervenga en esferas prácticas que requieren una orientación racionalmente fundada. De esta forma, la ética de las organizaciones ha logrado avances significativos, que apuntan al desarrollo de sistemas integrados de gestión ética (García Marzá, 2004). Estos sistemas buscan penetrar en la entraña misma de las instituciones, evitando críticas como esta: que la ética puede tener una función ideológica, función recogida en la frase "la ética lava más blanco" al referirse a la ética como mero instrumento de márketing e imagen externa. De este modo, es una simple técnica para la manipulación y la legitimación de estructuras claramente injustas. En lugar de ética es cosmética (García Marzá, 2004: 20-21).

\subsection{Bienes internos y bienes externos en las instituciones}

Un marco delimitativo complementario es la identificación de las exigencias propias de los "bienes internos" de cada "práctica social" (MacIntyre, 1987: 233). Por ello denominamos la misión propia de cada función o institución, que define el sentido profundo de una organización humana, y los roles que demanda. Esta noción de práctica se arraiga en el concepto aristotélico de praxis, que describe una acción individual que tiene su fin en sí misma, y cobra sentido precisamente de buscar ese fin. El autor sostiene en Tras la virtud que una práctica consiste en una:

Forma coherente y compleja de actividad humana cooperativa, establecida socialmente, mediante la cual se realizan los bienes inherentes a la misma, mientras se intenta alcanzar los modelos de excelencia que son apropiados a esa forma de actividad y la definen parcialmente (MacIntyre, 1987: 233).

Esta perspectiva exige desentrañar los objetivos, el "reino universal de los fines" (Kant, 1980: 124) de cada institución, y dentro de ellas, las de cada persona en particular. Esta distinción presupone que los "bienes externos" de una institución, como el generar ingresos, adquirir prestigio, capacidad de influencia o poder, crecer o expandirse, no debe impedir que se busque en forma prioritaria los "bienes internos" de esa institución. Por "bienes internos" se entiende el rol social que justifica la existencia de esa organización humana. Por ejemplo, en el caso de una Iglesia, los "bienes externos" son legítimos y adecuados de buscar y alcanzar, tanto y en 
cuanto no lleven a la institución eclesial a descuidar su misión fundamental, de carácter religioso, pastoral y humanitario. Tal como afirma MacIntyre:

En realidad, tan íntima es la relación entre prácticas e instituciones y, en consecuencia, la de los bienes externos con los bienes internos a la práctica en cuestión, que instituciones y prácticas forman típicamente un orden causal único, en donde los ideales y la creatividad de la práctica son siempre vulnerables a la codicia de la institución, donde la tensión cooperativa al bien común de la práctica es siempre vulnerable a la competitividad de la institución. En este contexto, la función esencial de las virtudes está clara. Sin ellas, sin la justicia, el valor y la veracidad, las prácticas no podrían resistir al poder corruptor de las instituciones (1987: 245).

En coherencia con este enfoque la corrupción institucional se puede definir como el predominio y hegemonía del "reino de los medios" (bienes externos) por sobre el "reino de los fines" (bienes internos) que deberían constituir la actividad prioritaria y constante de una institución. Las organizaciones que se corrompen son aquellas que han perdido esta jerarquización deontológica en sus marcos de deliberación moral. Para entender las razones que llevan a este descentramiento organizacional de las metas prioritarias, cabe analizar ciertas dinámicas propias de los procesos de institucionalización. Recurriendo a MacIntyre podemos analizar el "poder corruptor de las instituciones" como una tendencia a hacer de la organización, de su pervivencia y crecimiento, un fin en sí mismo. Ninguna institución puede sentirse inmune a esta predisposición, ya que el vínculo entre fines y medios puede ser tan estrecho que no es fácil discernir sus límites. Crecer institucionalmente y permanecer en el tiempo se puede identificar con alcanzar de forma excelente los fines de la organización. El punto clave pasa entonces por someter esas intenciones declaradas, esos fines justos, a un análisis de sus medios. En la opinión de Goulet, esto significa ejercitar la ética institucional como "medio de los medios" (1999: 34), es decir, como procedimiento de validación y análisis phronético a nivel intra-institucional.

De allí la necesidad de implementar modelos de gestión ética que aporten criterios pragmáticos en esta tarea. Una institución puede lograr mantener como prioridad la búsqueda de sus "bienes internos" si logra desarrollar lo que García Marzá ha definido con el concepto de "recurso moral", que entiende como "aquellos recursos que más aumentan cuanto más se utilizan, y desaparecen si no se hace uso de ellos". Los recursos morales de las instituciones son los que permiten que se resista al "poder corruptor de las instituciones" (García-Marzá 2004: 239) por medio de 
capacidades prácticas de generar criterios eficaces de alerta y rectificación, que pueden ser gestionados comunicativamente y no mediante el cálculo estratégico.

2. ClAVE DE LECTURA DE LA CORRUPCIÓN FRENTE A LA REALIDAD ECLESIAL CHILENA

La institución eclesial, dado su tradición e historicidad ha gozado sin cuestionamientos de la confianza de la ciudadanía, incluso ha sido leída desde un manto de inocencia, lo que la hacía intocable.

La caída del velo ha sido un proceso lento, doloroso, contundente. Se podría sostener que se generó una ruta comunicacional con respecto a los abusos y los encubimientos. En este proceso el papel de los medios de comunicación fue fundamental, ya que son ellos los que empujan y colocan en el tapete como noticia prioritaria la corrupción de la jerarquía, generando empatía con las víctimas y suscitando el reclamo de la sociedad civil.

Los primeros reportajes que empezaron a impactar en los medios de comunicación que tuvieron eco en la sociedad civil, fue el programa de Informe Especial, el 26 de abril del año 2010. Se puede señalar como un hito, explicitando los abusos de poder, de conciencia y sexuales de referentes eclesiásticos en contra de laicos, en donde se evidenciaba la impunidad y el encubrimiento de altos jerarcas de la Iglesia, desconociendo los testimonios de las víctimas, James Hamilton, Juan Carlos Cruz, José Andrés Murillo ${ }^{1}$, el ex seminarista Luis Lira y Fernando Batlle. Todos ellos integrantes de la Pía sociedad sacerdotal de Karadima², párroco de la iglesia Sagrado Corazón del Bosque, emplazada en una comuna acomodada de Santiago de Chile.

1 Víctimas emblemáticas de abuso sexual y psicológico que realizaron denuncias por escrito a la jerarquía de la Iglesia, como también a través de los medios de comunicación masiva (Diario y televisión) narrando su historia de vida y las atrocidades a las que fueron sometidos. Esas denuncias fueron acogidas transversalmente por la ciudadanía. De vital importancia fueron los medios de comunicación, que transfirieron la información como efecto multiplicador a nivel mundial. En el año 2010, Hamilton, Cruz y Murillo, junto con Juan Pablo Hermosilla, crean la "Fundación para la Confianza" con el fin de apoyar a niños $y$ niñas víctimas de abuso sexual; ver http://www.paralaconfianza.org/fundacion/

2 Fernando Karadima, es un ex sacerdote chileno y párroco de la iglesia Sagrado Corazón del Bosque, acusado de causar el mayor escándalo de abusos sexuales y psicológicos en la Iglesia Católica de Chile. Se han escrito al respecto los siguientes libros Los secretos del imperio Karadima; Karadima, el señor de los infiernos; El fin de la inocencia; y una película, denominada "El bosque de Karadima" (BBC, 2018b). 
Los que denunciaban, según la jerarquía, eran considerados enemigos de la Iglesia, porque la desprestigiaban queriendo desestabilizarla y acallarla frente a la agenda ética de los gobiernos como la legislación del aborto en tres causales, el matrimonio de unión civil y la ley de identidad de género. Como efecto multiplicador fueron apareciendo otros escándalos en diversas diócesis como Chillán, Valparaíso, Talca, Osorno, Punta Arenas, Cofradía de Rancagua ${ }^{3}$, caso marista ${ }^{4}$, caso de Cristián Precht ${ }^{5}$, entre otros.

Es interesante resaltar que la política de encubrimiento y de invisibilización ha sido tan poderosa que, si no hubiese sido por los medios de comunicación, las instituciones eclesiales no habrían dado los pasos para subsanar esta situación. Hubo mediaciones externas para levantar una acusación fundada que el mismo Papa Francisco en su visita a Chile no dimensionó del todo. $\mathrm{Al}$ respecto, la pregunta que realizó la periodista de la Radio Bio Bio $^{6}$ al Papa respecto del Obispo Barros, donde Francisco responde que quiere pruebas, conmocionó al pueblo de Dios. Esa pregunta y esa respuesta, representa un punto de inflexión para que se abordaran los casos de abuso y se realizara una investigación exhaustiva.

Este fenómeno social, permitió que se levantaran las voces de diversas organizaciones de víctimas y sobrevivientes tales como los Laicos de Osorno, Red de Sobrevivientes de abuso sexual eclesiástico en Chile, Red Nacional de Laicos, voces católicas, entre otros, quienes se legitiman al ser reconocidos por entidades internacionales como la ONG estadounidense Bishop Accountability y la comisión Scicluna, delegación del Vaticano que recoge las denuncias de las víctimas en misión oficial, luego de la visita del Papa Francisco a Chile. Esto produce tensiones, puesto que la institución eclesial chilena pareciera que no puede autorregularse y los obispos son citados al Vaticano por el Papa, quien entrega una carta de reflexión que se hizo pública (Francisco, 2018b). En ella les plantea que el pueblo de Dios está herido por lo mal que se han enfrentado los casos de abuso, les hace ver que se ha perdido el espíritu profético tan característico de la Iglesia chilena citando principalmente a San Alberto Hurtado y al Cardenal

\footnotetext{
3 Se consigna que hubo una cultura de encubrimientos que impidió que los hechos de abusos fueran revelados y sancionados (Cooperativa, 2018).

4 Abusos sexuales, psicológicos y espirituales contra niños de colegios de la Congregación Marista que datan desde el año 1970. Estos abusos fueron denunciados por los sobrevivientes (TVN-24 horas, 2018).

5 Cristian Precht, ex sacerdote, ícono de la defensa de los derechos humanos durante la dictadura militar en los años 70 y 80, dirigió la Vicaría de la solidaridad, prestando auxilio a los perseguidos políticos (BBC, 2018a).

$6 \quad$ Tras la visita del papa Francisco a Chile, una periodista de la Radio Bio Bio (2018) pregunta a Francisco respecto de su apoyo al obispo de Osorno.
} 
Raúl Silva Henríquez. Les reprocha haber construido una iglesia bajo los paradigmas de "mesianismo, elitismos, clericalismos, son todos sinónimos de perversión en el ser eclesial; y también sinónimo de perversión es la pérdida de la sana conciencia de sabernos pertenecientes al santo Pueblo fiel de Dios" (Francisco, 2018b: 7). Al finalizar la visita, todos los obispos presentan la renuncia como una manera de enfrentar la crisis de la institución eclesial chilena por medio de nuevos nombramientos que el Papa pudiese hacer en el corto y mediano plazo.

Esta situación conmocionó al pueblo de Dios y a otros grupos que adhieren a la causa de las víctimas desde fuera de la Iglesia, es por este motivo que ante el dolor de la situación el Papa escribe la carta al Pueblo de Dios que peregrina en Chile y, con respecto a este proceso, plantea que:

Todo el proceso de revisión y purificación que estamos viviendo es posible gracias al esfuerzo y perseverancia de personas concretas que, incluso contra toda esperanza o teñidas de descrédito, no se cansaron de buscar la verdad; me refiero a las víctimas de los abusos sexuales, de poder, de autoridad y a aquellos que en su momento les creyeron y acompañaron (Francisco, 2018a: n. 3).

Ciertamente, esta situación ha producido el derrumbe de paradigmas que obliga a problematizar la misión de la Iglesia como pueblo de Dios, al mismo tiempo que se convive con la des-confianza en la institución eclesial. Después de este largo proceso de denuncias, encubrimientos, invisibilizaciones al pueblo de Dios y a la ciudadanía, se asume que no solamente hay crisis eclesial, sino que, verdaderamente, se está viviendo un hecho histórico de corrupción de la institución, pues "la fisonomía de la corrupción se perfila no sólo como un problema de violación de normas (ilegalidad), sino fundamentalmente como un problema de violación de valores (ilegitimidad)" (Leis, 2009: 11). Entonces, ¿desde qué prisma observamos? ¿Desde qué lugar? ¿Con qué clave de lectura?

Se impone sobre la institución eclesial la carga histórica de ser épocal, desplegando una hermenéutica de acuerdo a los signos de los tiempos, cuyo resultado son las infinitas interpretaciones que se adecúan a las nuevas traducciones de un ser humano que plantea, cuestiona y busca respuestas. Encontrándose con una institución del antitestimonio, que influye e impacta cada vez menos, su impronta misionera se ve disminuida por autoritarismos, abusos, poca transparencia en las conductas y en las finanzas.

En este contexto, Leis señala que "la corrupción tiene muchas caras y no es generalmente un acto aislado, sino más bien un sistema de comportamiento, una especie de cadena comunicacional en negativo" (2009: 17); además, dice que requiere como soporte algunas condiciones para que 
opere, "abuso de poder, controles sociales e institucionales inexistentes o débiles, ética permisiva o cultura de la normalidad" (Leis, 2009: 20). A esto se añade la red de encubrimiento que posibilita la impunidad, a través del tráfico de influencia y favores de las cofradías, que les permite ejercer conductas inadecuadas y que se amparan en la confianza irrestricta de los que tienen menos poder, para traspasar las fronteras físicas y psicológicas de lo moralmente permitido.

Lo anterior, empequeñece y jibariza la participación efectiva y comprometida de los laicos y laicas, puesto que se ha tomado conciencia que la corrupción es un fenómeno enraizado y que requiere de recursos morales, tales como transparencia, verdad, justicia y reparación. En el mismo sentido, Francisco (2013) plantea que "la mundanidad espiritual, que se esconde detrás de apariencias de religiosidad e incluso de amor a la Iglesia, es buscar, en lugar de la gloria del Señor, la gloria humana y el bienestar personal" (n. 93).

La corrupción tiene un componente personal, dado que es una disposición que se opone al bien común, y a la vez, "es un sistema de comportamiento o red en la que participan un poder fáctico (individual o colectivo), portador de intereses particulares y con poder de influencia para garantizar condiciones de impunidad" (Leis, 2009: 11). El problema se complejiza cuando esas prácticas antiéticas se instalan en lo más profundo de los sistemas, de maneras tan arraigadas que es difícil desentrañar.

La institución eclesial experimenta una crisis profunda por los casos ocurridos de pedofilia y abuso sexual a menores de edad y el encubrimiento de la jerarquía, lo que ha significado el repudio social y la empatía a las víctimas y sobrevivientes que colocaron el tema en la justicia en los medios de comunicación, luego de un largo periplo denunciando a tribunales civiles y eclesiales. El Papa Francisco ha señalado que ante los casos de abusos ocurridos es necesaria una renovación y conversión eclesial que sea sana y a largo plazo. Planteando además que:

Seremos fecundos en la medida que potenciemos comunidades abiertas desde su interior y así se liberen de pensamientos cerrados y autorreferenciales llenos de promesas y espejismos que prometen vida pero que en definitiva favorecen la cultura del abuso (Francisco, 2018a: n. 5).

En la actualidad, el pueblo de Dios está en shock, puesto que se han derribado paradigmas de lo que históricamente ha significado la seguridad, la confianza, la incondicionalidad. Tal vez hay quienes aun viven en la etapa de la negación, que significa buscar respuestas inexistentes, sin poder bajar el velo de la incredulidad. En este contexto, Francisco afirma que "urge (...) generar espacios donde la cultura del abuso y del encubrimiento 
no sea el esquema dominante; donde no se confunda una actitud crítica y cuestionadora con traición” (2018a: n. 4). Por eso, como se señaló anteriormente, es necesario generar condiciones para el diálogo, de lo contrario se cae en el poder corruptor de las instituciones. Y la Iglesia como pueblo de Dios sabe dialogar, pues la renovación impulsada por el Concilio Vaticano II se fundamentó precisamente en esto. De hecho, Pablo VI (1964) en Ecclesiam Suam, hizo del diálogo un requisito irrenunciable para la vida de la Iglesia y su relación con otras religiones y sujetos sociales.

Es necesario considerar que cuando los hechos de corrupción han golpeado a otras instituciones, la sociedad civil se hunde en una actitud de desesperanza aprendida como condición sine qua non de los sistemas políticos y económicos, sobre los que solo se puede observar sin tener injerencias, o bien, discutir o problematizar en el plano privado a puertas cerradas o, por último, denunciar al modo de los indignados. Pero cuando se trata de la Iglesia, el asunto es distinto porque los modelos y paradigmas se derriban, puesto que existe un imaginario social respecto de su probidad, integridad y honestidad. $\mathrm{Al}$ respecto, Francisco advierte:

¡Dios nos libre de una Iglesia mundana bajo ropajes espirituales o pastorales! Esta mundanidad asfixiante se sana tomándole el gusto al aire puro del Espíritu Santo, que nos libera de estar centrados en nosotros mismos, escondidos en una apariencia religiosa vacía de Dios. ¡No nos dejemos robar el Evangelio! (2013, n. 97).

Sin lugar a dudas, la corrupción de la institución eclesial tiene como fundamento la pérdida del Evangelio y suscita que los fieles también lo pierdan por el antitestimonio. Como se señaló en el primer apartado, la Iglesia pierde el bien interno y, por sus características, esto significa perderlo todo. Esto se refleja en cifras que, según una encuesta realizada por Latinobarómetro (2018), ha reducido la confianza de los chilenos en la institución eclesial siendo un factor determinante el caso Karadima. Se produce, además, una reducción notable en el número de las personas que se consideran católicas (de un 61\% en el 2010 a un 45\% en el 2017), a la vez que aumentan aquellos que se declaran sin religión (de un $18 \%$ en el 2010 a un $35 \%$ en el 2017).

¿Cuáles son los intereses que debe defender la Iglesia? ¿Cómo se vincula con la lucha contra la violencia de género, los sueldos de miseria, el reconocimiento a la diversidad sexual, étnica y religiosa, los nuevos racismos y los nuevos nacionalismos? El llamado es a encarnar las enseñanzas de Jesús y la esperanza de la vida eterna, a constituirse en un ejemplo de vida y de espiritualidad, a consolidarse como una institución centrada en el bien interno que es el Evangelio encarnado en la vida del pueblo. Por el 
contrario, quienes promulgan una Iglesia que se preocupa solo de los bienes externos, han quedado en la periferia del auténtico significado de la Iglesia pueblo de Dios. Esta forma de vivir la Iglesia se ha dado principalmente en la jerarquía, cuyas conductas y prácticas pretenden sostener una cultura de cristiandad donde los bienes de la institución y los privilegios se sostenían en su unión con el Estado. Si bien en Chile, la Iglesia y el Estado se separan en la Constitución de 1925, lo cierto es que la cosmovisión de un país mono cultural y con predominio de la catolicidad, ha permanecido en el inconsciente colectivo de la ciudadanía, incitada por el mundo clerical.

Según González de Cardedal (2016), el paso de la cristiandad a la cristianía, ha sido un proceso histórico complejo donde la nostalgia de la cristiandad no ha permitido abrir el sendero a una Iglesia que se sitúe en diálogo con la sociedad civil y no al margen de ella, como en una burbuja de protección donde su quehacer esté por encima de la normativa vigente. Continuar con la lógica de la cristiandad es hacer que el cristianismo se convierta "en una pieza de museo o en una posesión de pocos" (Francisco, 2013: n. 95), desarrollando "la psicología de la tumba, que poco a poco convierte a los cristianos en momias de museo" (Francisco, 2013: n. 83).

El proyecto de la cristiandad, desechado por el Concilio Vaticano II (Mifsud, 2015), ha sido sostenido paradójicamente por la institución eclesial, incluso se podría afirmar que hay nostalgia de cristiandad en algunos miembros de la jerarquía. De tal modo que, frente a los abusos, lo primero que aflora es querer cuidar la institución eclesial, y es ahí cuando se produce la red de encubrimiento cuyas consecuencias fueron nefastas, ya que la jerarquía "dejó de mirar y señalar al Señor para mirarse y ocuparse de sí misma. Concentró en sí la atención y perdió la memoria de su origen y misión" (Francisco, 2018b: 6). Ante esta realidad de corrupción, de perder el bien interno, Francisco afirma:

El "nunca más" a la cultura del abuso, así como al sistema de encubrimiento que le permite perpetuarse, exige trabajar entre todos para generar una cultura del cuidado que impregne nuestras formas de relacionarnos, de rezar, de pensar, de vivir la autoridad; nuestras costumbres y lenguajes y nuestra relaci6n con el poder y el dinero (Francisco, 2018a: n. 4).

El "nunca más" que pronuncia Francisco es un llamado urgente a la renovación de la Iglesia. Ella se realiza desde el sufrimiento inocente de las víctimas de abuso de poder, de conciencia y sexual perpetrados por la institución eclesial. De alguna manera, la profecía de Isaías (Is 42,1-4 49,1$16 ; 50,4-10)$ en que la renovación de la fe de Israel vendría a través de la figura del siervo sufriente, se hace presente hoy en la historia del pueblo 
de Dios que peregrina en Chile. Así, la denuncia de las víctimas requirió de valentía, el silencio se transformó en una voz amplificada que logró agrietar las murallas de la cristiandad, que, frente a la denuncia del abuso, se escandalizó, miró con horror y se paralizó.

\section{PROPUESTA A PARTIR DE LA GOBERNANZA Y LA TRANSPARENCIA}

Es evidente que la Iglesia Católica no ha desarrollado una reflexión sistemática sobre la noción de transparencia institucional. Esto se constata en la redacción del Código de Derecho Canónico. En el principal texto legal de la Iglesia el concepto mismo "transparencia" no aparece mencionado explícitamente en ninguna ocasión. En contraste, la noción de "secreto" aparece treinta y ocho veces, "discreción" en siete y la palabra "ocultar", en sus diferentes conjugaciones, en diecisiete (Ramis, 2011: 9). Es sintomático que la noción de "secreto" y sus variantes tenga una relevancia tan importante en la legislación eclesiástica.

No se trata de cuestionar la legitimidad o el sentido de algunas de estas normas que prescriben secreto o sigilo, que se pueden justificar claramente en su contexto. Lo que debería preocupar es la ausencia de una reflexión sobre el valor de la transparencia en el gobierno y en la administración de una institución compleja como es la Iglesia. Al respecto el grupo de investigación sobre el sostenimiento de la Iglesia Católica en España señala respecto a esta ausencia:

El Código de derecho canónico de 1983 no especifica cómo debe entenderse esta rendición de cuentas y cuáles son sus características. En virtud del principio de subsidiariedad, ampliamente presente en la materia patrimonial, deberá ser la legislación particular la que establezca estas condiciones en ambas modalidades (GISIC, 2011).

Una agenda de cambio organizacional, es decir desde la gobernanza, debería incluir los siguientes aspectos mínimos: reconfigurar el organigrama pasando desde la jerarquía a la corresponsabilidad, de un modelo de gestión taylorista (Ramis, 2017: 229), basado en el mando y la obediencia, a un modelo de gestión participativo, basado en corresponsabilidad. Fortalecer la autoconciencia de la cultura organizacional en orden al logro de los "bienes internos" de la institución, identificados por medio de significados compartidos y esquemas de interpretación que recreen ese "sentido común" colectivo a lo largo del tiempo. Ese proceso permitiría fortalecer y cambiar el ethos de la Iglesia como organización, factor clave para 
dar coherencia a sus decisiones y crear adhesión e identidad a sus integrantes. Una Iglesia autoconsciente de su propia cultura organizacional podría sintonizar con las demandas éticas de la sociedad actual.

Respecto a la transparencia se identifican dos métodos fundamentales que permiten a las instituciones, ya sean públicas o privadas, dar cuenta de esta demanda social: la agenda de transparencia activa y la de transparencia pasiva. Las medidas de transparencia activa se basan en un diseño comunicativo que busca difundir información sin que nadie lo solicite de antemano, como una manera de transparentar la gestión. Una forma común de hacerlo consiste en mantener en sitios web institucionales información permanente y actualizada.

Las medidas de transparencia pasiva buscan garantizar el acceso a la información de carácter público que no está publicada en el sitio Web o en otro órgano de publicidad. Basándose en este criterio cualquier persona tendría derecho a solicitar acceso a información, sin mediar explicaciones y para el uso que estime conveniente. Con el fin de garantizar este procedimiento se aconseja constituir una comisión específica que permita promover la transparencia institucional, fiscalizar el cumplimiento de las normas y garantizar el derecho de acceso a la información. Idealmente toda solicitud que se ha formulado en los marcos prescritos a tal fin debería tener una respuesta de acuerdo a un plazo predeterminado. Por otra parte, si la institución resuelve que no corresponde entregar la información, entonces, debería argumentar sólidamente los motivos de esta denegación.

Finalmente, también es importante garantizar un marco de relaciones laborales mínimamente consensuado, que incluya al personal consagrado, voluntario y a los profesionales y trabajadores remunerados en las obras e instituciones, que impida la potencial instrumentalización de las personas. Es en este campo donde cabe la elaboración y sanción de protocolos de conducta, denuncia de abusos, y canales de acción ante emergencias y situaciones de crisis que cuenten con el acuerdo al menos tácito de los involucrados. Los instrumentos prácticos que pueden hacer efectivo este objetivo son al menos los siguientes (García Marzá, 2004: 123):

- Códigos éticos: documentos formales donde se exprese la voluntad y la disposición de la institución para el reconocimiento y satisfacción de los intereses de todos los involucrados. No pueden basarse simplemente en la doctrina eclesial, ya que deben tener la pretensión de satisfacer intereses racionales universalizables, más allá de la vida eclesial, en tanto la Iglesia es una institución pública que ejerce roles e influencia más allá de sí misma. 
- Comités de ética: se conciben cómo espacios de la razón pública en la institución, ámbito para el seguimiento y control de los compromisos adquiridos, así como para la deliberación y la búsqueda de intereses comunes y generalizables.

- Auditorias éticas: valoración del cumplimiento del contrato moral, de la consistencia entre lo que se dice y lo que se hace. Se deben realizar por actores externos a la institución.

La mayor dificultad que complejiza la transformación institucional del catolicismo no radica en la necesidad de modificar los marcos jurídicocanónicos sino, sobre todo, de las fuentes eclesiológicas que dan coherencia teológica a su institucionalidad. No se trata de apostar a un tipo de transparencia absoluta que no podría ser más que una pesadilla orwelliana, entendida como una situación o régimen donde se manipula la información y se mantiene vigilada a la población. Lo que interesa en este proceso es consolidar una concepción de la convivencia ad intra y ad extra ecclesiam donde el poder se encuentre más diseminado y donde el equilibrio entre la institucionalidad centralizada y las demandas de la opinión pública se balanceen de forma más equitativa. Este es un tipo de ejercicio que no se consigue con la ausencia de regulaciones o controles, sino por medio de un marco reglamentario justo basado en criterios universalizables.

Todo lo anterior, que tiene por sustento la ética de las instituciones, no es ajeno a la fe cristiana; de hecho, en la legislación judía se advertía a las autoridades: "no torcerás el derecho, no harás acepción de personas, no aceptarás soborno, porque el soborno cierra los ojos de los sabios y corrompe las palabras de los justos" (Dt 16, 19). A su vez, la tradición cristiana, a partir de las enseñanzas evangélicas ha desarrollado a través de los siglos una enseñanza social que desde el siglo XIX se ha plasmado en la doctrina social de la Iglesia cuyos ejes fundamentales se basan en el bien común, la justicia y el amor (Consejo Pontificio Justicia y Paz, 2005). Por tanto, los caminos de solución de la institución eclesial desde la gobernanza y la transparencia se fundamentan en ser fiel a sus propios principios.

A su vez, la institución eclesial tiene una responsabilidad como pueblo de Dios en la sociedad civil, no como el soporte ético de la ciudadanía, pues esta convicción es propia de la cristiandad, sino coma aquella que camina fraternalmente con la humanidad, al modo de una Iglesia Samaritana. En este sentido, hay mucho por hacer; por ejemplo, ante los problemas sociales y políticos como la marginación, las migraciones forzosas, los genocidios, la discriminación, el hambre, la pobreza, las guerras, la desconsideración a los derechos humanos fundamentales. Todo ello requiere de líderes transformacionales. ¿Se ha preparado la institución para acompañar 
el sufrimiento de sus hermanos?, ¿ha sido testimonio de credibilidad, caridad, justicia, misericordia y humanidad? Francisco advierte que "quien ha caído en esta mundanidad mira de arriba y de lejos, rechaza la profecía de los hermanos, descalifica a quien lo cuestione, destaca constantemente los errores ajenos y se obsesiona por la apariencia" (Francisco, 2013, n. 97).

$\mathrm{Al}$ respecto, una de las consecuencias más tristes de la corrupción institucional son los efectos que tiene en los más pobres, pues empresas que antes de estos hechos eran colaboradores habituales para las distintas obras eclesiales hoy se cuestionan el continuar con esa ayuda. Los colegios católicos, como lugares seguros de educación integral hoy se ven con sospecha, aunque en esos lugares nunca haya habido un abuso, lo mismo sucede con otras fundaciones que tienen que argumentar y fundamentar su quehacer. Finalmente, jóvenes que se alegraban de seguir una vocación religiosa y laical, hoy son temerosos de seguir este camino debido a la cultura del abuso.

Por otra parte, cuando los paradigmas económicos neoliberalistas levitan, asumiendo el poder bursátil, y el capital se adueña del mundo, en donde todo es negociable, entonces surge para la institución católica la oportunidad de asumir un liderazgo transformacional y en constituirse en una alternativa de sentido de vida para muchos que anhelan una Iglesia que sea expresión de vida comunitaria unida a las enseñanzas del Maestro. Sin embargo, para que ello ocurra, debe generarse un giro ético que reposicione los valores fundamentales del cristianismo, lo cual requiere un cambio profundo en la gobernanza, lo que Aparecida (CELAM, 2008) llamó e invitó a la renovación de las estructuras.

\section{CONCLUSIONES}

Frente a la corrupción y el abuso arraigado tanto en las instituciones políticas, económicas, sociales y eclesiales, se debe levantar como imperativo ético el compromiso y la denuncia desde la responsabilidad ciudadana. Este derecho se desvanece toda vez que se impide a través de coacción o indiferencia.

Toda corrupción lo que hace es anteponer los bienes externos a los internos, los bienes por sobre los fines. Esto explica los mecanismos de protección institucional, el encubrimiento por sobre los valores a los que debe responder. Esto deslegitima a la propia institución dado por las incoherencias entre los discursos y las prácticas. Debe usarse valoración interna y no por cálculos a corto plazo. Creerse el cambio para modificar conductas aprendidas por mucho tiempo, que ya se constituyen hábitos arraigados. Colocar intención y empeño para cambiar esos hábitos, puesto 
que no son espontáneos y requieren mediaciones y aplicación de herramientas de gobernanza. Este cambio profundo, desde adentro, requiere cambios de estructuras, demandas de la época, saber escuchar, discernir los signos de los tiempos, y oportunidad de regenerar la institución.

La denuncia dentro de las instituciones, no es un escándalo, ni una infidelidad, sino que es un posibilitador de cambio y de reconstrucción para enfrentar la grave crisis de la institución eclesial, de allí la lógica del "nunca más". El cuestionamiento hace caer el velo e induce al cambio necesario en la Iglesia, para que cada uno asuma su misión desde sus propios roles, funciones y carismas.

Este artículo ha pretendido aportar desde la ética de las instituciones a la problemática de la corrupción aplicando un lenguaje de gestión a la institucional eclesial como una forma de enfrentar la corrupción. Desde esta perspectiva no se demoniza el hecho de entenderse como institución, el problema es cuando ella no es fiel a sí misma perdiendo la dimensión de pueblo de Dios. Esta responsabilidad no es solo de la jerarquía, sino de toda la Iglesia; de hecho, el Papa impulsa a los laicos a involucrase y a denunciar el abuso:

Exhorto a todo el Santo Pueblo fiel de Dios que vive en Chile a no tener miedo de involucrarse y caminar impulsado por el Espíritu en la búsqueda de una Iglesia cada día más sinodal, profética y esperanzadora; menos abusiva porque sabe poner a Jesús en el centro, en el hambriento, en el preso, en el migrante, en el abusado (Francisco, 2018a: n.7).

Para llevar adelante lo importante, poner a Jesucristo en el centro a través del hermano que sufre, es necesario poseer mecanismos de una buena gobernanza institucional los cuales son viables de implementar en la Iglesia y dejar de creer que ella puede y debe ser la excepción.

En primer término, se debe considerar la institución eclesial dentro de los parámetros de la legislación civil, desplegando una cultura de la evaluación permanente y circular, de tal modo, que aquellos que realizan funciones administrativas deban informar y dar cuenta de sus acciones funcionales y de probidad a todas las instancias jerárquicas, laicales y cívicas, donde esa información esté disponible para todos aquellos que quieran hacer uso de ella. Entonces, se trata de cambiar el paradigma de la institución eclesial como élite y círculo cerrado, a una comunidad evangelizadora que evalúa constantemente sus procesos.

De esta manera, es posible contar con una cultura de la transparencia de las finanzas, que promueva la opción por los pobres y ello sea coherente con la vocación sacerdotal, religiosa, diaconal o laical. De esta manera, el 
discernimiento vocacional debería acentuar la vida de servicio donde existen diversos carismas y no creerse el representante de Dios en la tierra, con privilegios propios de una persona que está en un rango superior al resto de los fieles y la ciudadanía. Así, el proceso de iniciación cristiana y acompañamiento permanente se torna un imperativo para todos quienes forman parte del Pueblo de Dios y sobre todos para aquellos que optan por carismas que realizan funciones de gobernanza institucional.

A su vez, es necesario constituir una nueva relación, horizontalizando la institución, donde los laicos se constituyan en co-actores de la gobernanza para establecer puentes éticos al momento de enfrentar temas complejos como son los abusos de poder, de conciencia y sexual. Además, nunca hay que perder de vista que la sociedad evalúa a la Iglesia, y lo hace desde aquello que más aparece en los medios de comunicación y en percepciones personales, por tanto, esta situación de corrupción ha valido el descrédito e ilegitimidad de la comunidad eclesial sin hacer diferencias en cada uno de sus actores. Al respecto, el Papa señala:

Seríamos injustos si al lado de nuestro dolor y nuestra vergüenza por esas estructuras de abuso y encubrimiento que tanto se han perpetuado y tanto mal han hecho, no reconociéramos a muchos fieles laicos, consagrados, consagradas, sacerdotes, obispos que dan la vida por amor en las zonas más recónditas de la querida tierra chilena (Francisco, 2018a: n. 6).

Lamentablemente, la corrupción de la institución eclesial, eclipsa estos testimonios de vida evangélica. Es por eso que las herramientas de la gobernanza y la trasparencia, proveniente de una racionalidad ética institucional ajena al pensamiento teológico, permitirían combatir la corrupción, en la medida que "la cultura del abuso y del encubrimiento es incompatible con la lógica del Evangelio" (Francisco, 2018a: n. 5). También es posible que aquellos que no toleran la corrupción sistemática piensen, desde la desesperanza aprendida, que este flagelo es irremediable; pero desde la misma fe cristiana se pueden encontrar esperanzas de cambio, considerando, además, que en la cotidianidad de la vida siempre es posible contar con los "santos de la puerta de al lado" (Francisco, 2018c: n. 7).

Finalmente, este artículo queda abierto a una propuesta eclesiológica que nazca desde el sufrimiento de las víctimas, de la organización de los laicos y de la renovación de la jerarquía, cuestión que necesita ser desarrollada desde una nueva teología que recoja la crisis como aprendizaje. 


\section{REFERENCIAS}

-BBC (2018a). Abusos sexuales en Chile: Cristián Precht, el sacerdote ícono de los derechos humanos que fue expulsado del sacerdocio por el papa Francisco. Disponible en https:/ / www.bbc.com/mundo/noticias-america-latina-45549815

-BBC (2018b). Quién es Fernando Karadima, el exsacerdote que causó el mayor escándalo de la Iglesia católica de Chile. Disponible en https:/ / www.bbc.com/mundo/noticias-america-latina-45686485

-Bio Bio (2018). Papa defiende a Barros: "El dia que me traigan una prueba voy a hablar, todo es calumnia". Disponible en https://www.biobiochile.cl/noticias/nacional/region-de-los-lagos/2018/01/18/papa-francisco-por-obispo-barros-eldia-que-me-traigan-una-prueba-voy-a-hablar.shtml

-CELAM (2008). Documento Conclusivo de Aparecida. V Conferencia Episcopal Latinoamericana y del Caribe. Santiago de Chile: CECH.

-Consejo Asesor Presidencial Contra los Conflictos de Interés, el Tráfico de Influencias y la Corrupción (2015). Informe final. Disponible en http:/ / www.minsegpres.gob.cl/wp-content/uploads/2017/04/Informe-del-Consejo-Asesor-Presidencial-Contra-los-Conflictos-de-Intereses-el-trafico-de-Influencias-la-Corrupcion.pdf

-Consejo Pontificio Justicia y Paz. (2005). Compendio de la doctrina social de la iglesia. Lima: Paulinas.

-Cooperativa (2018). Las acusaciones contra los obispos que investiga la Fiscalía. Disponible en https://www.cooperativa.cl/noticias/pais/iglesia-catolica/las-acusaciones-contra-los-obispos-que-investiga-la-fiscalia/2018-0913/164200.html

-Cortina, A. (1985). Razón comunicativa y responsabilidad solidaria: ética y politica en K.O. Apel. Salamanca: Sígueme.

-Costadoat, J. (2014). Francisco, Papa. Señal de grandes cambios. Santiago de Chile: San Pablo.

-Francisco (2013). Evangelii gaudium. Santiago de Chile: San Pablo.

-Francisco (2018a). Carta al Pueblo de Dios que peregrina en Chile. Disponible en http://w2.vatican.va/content/francesco/es/letters/2018/documents/papa-francesco_20180531_lettera-popolodidio-cile.html

-Francisco (2018b). El pasado 8 de abril, domingo de la Misericordia les envié una carta convocándolos a Roma. Disponible en http://www.t13.cl/noticia/nacional/latranscripcion-completa-del-documento-reservado-papa-entrego-obisposchilenos

-Francisco (2018c). Gaudete et exsultate. Santiago de Chile: San Pablo.

-García Marzá, D. (2004). Ética empresarial: del dialogo a la confianza. Madrid: Trotta.

-García Marzá, D. (2017). Corrupción: uso y abuso. Disponible en https:/ /www.elperiodicomediterraneo.com/noticias/contra/corrupcion-usoabuso_1082664.html

-GISIC (2011). Informe 2011. Disponible es http:/ /www.unav.es/centro/gisic/

-González de Cardedal, O. (2016). Ciudadanía y cristianía. Una lectura de nuestro tiempo. Madrid: Encuentro. 
-Goulet, D. (1999). Ética del desarrollo. Guia teórica y práctica. Madrid: IEPALA.

-Habermas, J. (1985). Conciencia moral y acción comunicativa. Barcelona: Península.

-Habermas, J. (1999). Teoría de la acción comunicativa I. Racionalidad de la acción y racionalización social. Madrid: Taurus.

-Informe Especial (2010). Reportaje el caso Karadima pederastía. Disponible es https: / / www.youtube.com/watch?v=Lil3MKjNeKo

-Kant, I. (1980). Fundamentación de la metafísica de las costumbres. Madrid: EspasaCalpe.

-Küng, H. (2013). ¿Tiene salvación la Iglesia? (J. M. Lozano-Gotor, Trad.). Madrid: Trotta.

-Latinobarómetro (2018). El Papa Francisco y la religión en Chile y América Latina. Disponible en http://www.latinobarometro.org/latNewsShow.jsp

-Leis, R. (2009). Retrato escrito de la corrupción. Panamá: Novo Art.

-MacIntyre, A. (1987). Tras la Virtud (A. Valcarcel, Trad.). Barcelona: Crítica.

-Martínez Navarro, E. (2000). Ética para el desarrollo de los pueblos. Trotta. Madrid.

-Mifsud, T. (2015). Encontrar la paz en tiempos de agobio. Una segunda conversión. Santiago de Chile: Mensaje.

-Pablo VI (1964). Ecclesiam Suam. Disponible en http://w2.vatican.va/content/paul-vi/es/encyclicals/documents/hf_p-vi_enc_06081964_ecclesiam.html

-Ramis, A. (2011). La transparencia institucional de la Iglesia Católica. Aproximaciones desde la ética del discurso. Cultura y Religión, 5(2), 5-18.

-Ramis, A. (2017). Bienes comunes y democracia. Critica del individualismo posesivo. Santiago: LOM.

-Scannone, J.C. (2016). La teología del pueblo. Raíces teológicas del Papa Francisco. Maliaño, Cantabria: Sal Terrae.

-TVN-24 horas (2018). Caso maristas: Sobrevivientes de abusos expresan reparos al cierre de las investigación y exigen antecedentes. Disponible en ttps://www.24horas.cl/nacional/caso-maristas-sobrevivientes-de-abusos-expresan-reparos-al-cierrede-las-investigacion-y-exigen-antecedentes-2813391

-World Bank (2014). Public Office, Private Interests: Accountability through Income and Asset Disclosure. World Bank. Disponible en https://openknowledge.worldbank.org/handle/10986/2320

Sumario: Introducción; 1. Ética y corrupción institucional; 1.1. Definiciones y perspectivas; 1.2. Corrupción y ética institucional; 1.3. Bienes internos y bienes externos en las instituciones; 2. Clave de lectura de la corrupción frente a la realidad eclesial chilena; 3. Propuesta a partir de la gobernanza y la transparencia; Conclusiones; Referencias. 